\title{
Variation in scale cortisol concentrations of a wild freshwater fish: habitat quality or seasonal influences?
}

\author{
A. Carbajal ${ }^{1}$, O. Tallo-Parra ${ }^{1}$, L. Monclús ${ }^{1}$, D. Vinyoles ${ }^{2 *}$, M. Solé ${ }^{3}$, S. Lacorte ${ }^{4}$, M. Lopez- \\ Bejar $^{1 *}$
}

${ }^{1}$ Department of Animal Health and Anatomy, Veterinary Faculty, Universitat Autònoma de Barcelona, 08193 Bellaterra, Barcelona, Spain

2 Department of Evolutive Biology, Ecology and Environmental Sciences, Universitat de Barcelona, Avinguda Diagonal 643, 08028, Barcelona, Spain

${ }^{3}$ Institut de Ciències del Mar (ICM-CSIC), Pg. Marítim de la Barceloneta 37-49, 08003, Barcelona, Spain

${ }^{4}$ Department of Environmental Chemistry, IDAEA-CSIC, c/Jordi Girona 18, 08034, Barcelona, Spain

*MLB and DV were co-principal investigators

Correspondence should be sent to Manel López-Béjar, Department of Animal Health and Anatomy, Veterinary Faculty, Universitat Autònoma de Barcelona, 08193 Bellaterra, Barcelona, Spain. e-mail address: manel.lopez.bejar@uab.cat; 
1

2 A significant body of literature suggests that aquatic pollutants can interfere with the

3 physiological function of the fish hypothalamic-pituitary-interrenal (HPI) axis, and eventually

4 impair the ability to cope with subsequent stressors. For this reason, development of accurate

5 techniques to assess fish stress responses have become of growing interest. Fish scales have been recently recognized as a biomaterial that accumulates cortisol, hence it can be potentially used to assess chronic stress in laboratory conditions. We, therefore, aimed to evaluate the applicability of this novel method for cortisol assessment in fish within their natural environment. Catalan chub (Squalius laietanus) were sampled from two sites; a highly polluted and a less polluted (reference) site, in order to examine if habitat quality could potentially influence the cortisol deposition in scales. We also evaluated the seasonal variation in scale cortisol levels by sampling fish at three different time points during spring-summer 2014. In each sampling, blood was collected to complement the information provided by the scales. Our results demonstrated that blood and scale cortisol levels from individuals inhabiting the reference site were significantly correlated, therefore increasing the applicability of the method as a sensitive-individual measure of fish HPI axis activity, at least in non-polluted habitats. Since different environmental conditions could potentially alter the usefulness of the technique, results highlight that further validation is required to better interpret hormone fluctuations in fish scales. Scale cortisol concentrations were unaffected by habitat quality although fish from the polluted environment presented lower circulating cortisol levels. We detected a seasonal increase in scale cortisol values concurring with an energetically costly period for the species, supporting the idea that the analysis of cortisol in scales reveals changes in the HPI axis activity. Taken together, the present study suggests that cortisol levels in scales are more likely to be influenced by mid-term, intense energetically demanding periods rather than by long-term stressors. Measurement of cortisol in fish scales can open the possibility to study novel spatiotemporal contexts of interest, yet further research is required to better understand its biological relevance. 
28 Keywords: Scales cortisol, bioindicator, habitat quality, pollution, stress, seasonality 
The analysis of circulating cortisol, the main glucocorticoid (GC) in teleost fish released after the activation of the hypothalamic-pituitary-interrenal (HPI) axis, has been by far the most common method used in stress response assessments (Mommsen et al., 1999; Schreck et al., 2016). Although acute stress responses, such as those initiated after an attack by a predator or severe storms, are imperative for fish homeostasis and survival, chronic stressors can negatively affect fish growth, reproduction and the immune system (Moberg and Mench, 2000; Pankhurst, 2011). The difficulty of obtaining baseline blood samples in wildlife, and the growing interest of conservation physiology in assessing chronic increases of cortisol (Dantzer et al., 2014), makes imperative the development of novel techniques to quantify fish HPI axis activity. In other taxa, integumentary structures such as hair, feathers, shed skin or claws are recently gaining attention since they provide an alternative way to measure hormone concentrations integrated over time (Berkvens et al., 2013; Bortolotti et al., 2008; Davenport et al., 2006; Matas et al., 2016). In this direction, fish scales have been recently recognized as a biomaterial that accumulates cortisol (Aerts et al., 2015; Carbajal et al., 2018). Thus far, no research has been done to examine the accurate time course over which scales accumulate cortisol. Similarly to the process described for corticosterone deposition on feathers (Bortolotti et al., 2008) or cortisol diffusion into the hair shaft (Russell et al., 2012), scales are vascularized by capillaries from which GC may diffuse into the matrix. As scales grow during the entire life of the fish (Elliott, 2000), cortisol measurements in this mineralized tissue could potentially integrate a longer period than any other tissue available. Despite hormone analysis in fish scales is a promising tool as it may provide integrated measures of cortisol, this method is not yet fully validated. To date, only one study has demonstrated the usefulness of scales as an indicator of long-term HPI axis activity in fish subjected to laboratory conditions (Aerts et al., 2015). Although these authors verified the biological relevance of scale cortisol levels, whether hormone concentrations in this media are proportional to their abundance in the bloodstream still remains to be explored. Establishing the relationship between scales and blood cortisol 
levels is crucial to increase the applicability of this novel method as a sensitive-individual

measure of fish HPI axis activity (Cook, 2012; Sheriff et al., 2011). In addition, this integrative technique has only been tested in farmed fish held under captivity. Nevertheless, given the structural characteristics of this matrix, the assessment of cortisol in fish scales is likely to present a promising applicability in natural environments.

Decline of wild fish populations, particularly those from freshwater systems, has been partly exacerbated by pollution (Ismail et al., 2017). Long-term exposure to pollutants, such as metals, pesticides, and other organics, can cause the chronic activation of the HPI axis, which as mentioned, can have detrimental consequences on fish performance (Mommsen et al., 1999; Scott and Sloman, 2004). Many researchers have explored the effects of environmental contaminants on the fish stress response, either measuring cortisol in blood (Hontela et al., 1992; Jorgensen et al., 2017; Miller et al., 2009) the surrounding water (Pottinger et al., 2016) or using whole-body homogenates (Belanger et al., 2016; King et al., 2016; Pottinger et al., 2013). Measurement of cortisol in scales could be a better option when an integrated measure of the HPI axis activity over longer periods is needed to enhance the "snapshot" of cortisol measurement.

When designing an experiment, several factors must to be considered in order to yield valuable, biologically relevant results (Johnstone et al., 2012; Killen et al., 2016; Schreck et al., 2016), and this is especially important when new matrices for endocrine assessment are being developed (Cook, 2012; Sheriff et al., 2011). In this context, a considerable amount of research has reported seasonal variation on cortisol levels (Belanger et al., 2016; Madliger and Love, 2014; Palme, 2005). Given that the assessment of cortisol in fish scales is a recent contribution (Aerts et al., 2015; Carbajal et al., 2018), it is crucial to understand the potential seasonal variation in scale cortisol concentrations (SCC) before using this method as an indicator of HPI axis activity in wild specimens. 
Taking into account these previous considerations, the present study was designed to explore the usefulness of fish scale cortisol analysis as a bioindicator in wild environments. As a further validation of the technique, we first aimed to evaluate whether the quantification of cortisol in scales reflects the HPI axis activity by individually comparing blood and scale cortisol levels in specimens of Catalan chub (Squalius laietanus). Second, we aimed to determine whether habitat quality affected the cortisol content in fish scales. Because of the long-term inhibitory effects of certain pollutants on the HPI axis activity (Gesto et al., 2008; Hontela et al., 1992; Leblond et al., 2001; Norris et al., 1999) we hypothesized that fish from a polluted habitat would present lower SCC compared to fish from a less polluted habitat. Additionally, we evaluated whether seasonality could influence SCC by sampling fish at the beginning-spring, middle-spring and beginning-summer. We hypothesized that higher concentrations of cortisol would be detected at the beginning of summer concurring with an energetically demanding period for this cyprinid (Colin et al., 2017).

\section{MATERIALS \& METHODS}

\subsection{Study area}

Fish sampling was carried out in the Ripoll River (Besòs basin) located in the north-east of Spain. The polluted habitat $\left(2^{\circ} 06^{\prime} 01.40^{\prime \prime} \mathrm{E} 41^{\circ} 34^{\prime} 17.88^{\prime \prime} \mathrm{N}\right)$ was located immediately after an industrial plant, strongly affected by the industry and urbanization. The less polluted site, henceforth referred to as the reference site $\left(2^{\circ} 03^{\prime} 24.07 \mathrm{E}^{\prime}{ }^{\prime} 41^{\circ} 38^{\prime} 45.05 \mathrm{~N}^{\prime}\right)$, was located on the same river but $2.7 \mathrm{~km}$ upstream from the highly degraded habitat. A small dam located between the two sampling sites prevented the passage of fish from one sampling point to the other. Analysis of physico-chemical water parameters (see section 2.3.) and chemical analysis of perand polyfluoroalkyl substances (PFAS) in the muscle of the fish collected at the two sites (see section 2.4.) were performed in order to certify that the selected habitats were correctly classified according to their pollution gradient: high pollution (henceforth referred to as the 
"polluted habitat") and low pollution (henceforth referred to as the "reference habitat") habitats. All procedures were conducted in accordance with the European Directive for animal experimentation (2010/63/EU) and approved by the Regional Government of Catalonia (Ref. AP/007). One of the co-authors holds a FELASA certificate that regulates the use of animals for experimental and other scientific purposes.

\subsection{Sampling times}

In order to study whether habitat quality influences SCC without accounting for seasonal variation, fish were sampled at the beginning of spring 2014 from the reference $(25 / 03 / 2014$; $n$ $=7$; mean body weight $\pm \mathrm{SD}=43.2 \pm 16.1 \mathrm{~g})$ and from the polluted habitat $(21 / 03 / 2014 ; \mathrm{n}=17$; mean body weight $\pm \mathrm{SD}=53.6 \pm 24.72 \mathrm{~g}$ ). To examine the seasonal influence on SCC, three consecutive sampling efforts were carried out in the reference habitat in spring-summer 2014. Samplings were performed in the early spring $(25 / 03 / 2014 ; \mathrm{n}=7$; mean body weight $\pm \mathrm{SD}=$ $43.2 \pm 16.1 \mathrm{~g})$, middle spring $(08 / 04 / 2014 ; \mathrm{n}=8$; mean body weight $\pm \mathrm{SD}=32.7 \pm 12.1 \mathrm{~g})$ and early summer $(16 / 07 / 2014 ; \mathrm{n}=17$; mean body weight $\pm \mathrm{SD}=46.3 \pm 26.0 \mathrm{~g})$. the scales with the "snapshot" of blood cortisol measurement. We evaluated circulating cortisol levels after a period of confinement since stressed-induced cortisol concentrations are known to provide a better understanding of the stress responsiveness (Romero, 2004). Stress-induced cortisol increases have been detected from as short as $2.5 \mathrm{~min}$ to as long as 120 -min in different fish species (Mommsen et al., 1999; Pankhurst, 2011). Accordingly, fish were caught with a portable electrofishing unit $(300 \mathrm{~V})$ and kept in tanks with the local river water for about $1 \mathrm{~h} \mathrm{in}$ order to trigger a stress response by capture and confinement. Fish were then euthanized with an overdose of MS-222, and immediately after, blood and whole body scales were collected. A portion of muscle was sampled for chemical analysis of PFAS. Sex, body weight, gonad weight and total length were recorded during post-mortem examinations. Fulton's condition factor, considered to reflect an individual's energetic state (Barton et al., 1998) was calculated according to the formula, $K=10^{6} \cdot$ body weight $(\mathrm{g}) \cdot$ total length $(\mathrm{mm})^{-3}$ (Goodbred et al., 
136 broadly used indicator of reproductive periods (Brewer et al., 2008), which was calculated with

137 the formula, GSI $=100 \cdot \operatorname{gonad}$ weight $(\mathrm{g}) \cdot$ body weight $(\mathrm{g})^{-1}($ Goodbred et al., 2015).

\subsection{Physico-chemical water parameters}

In the physico-chemical analysis, altered water parameters were observed in the polluted habitat compared to the reference site (Table 1). These values provide evidence that the habitat classified as polluted exhibits features commonly observed in disturbed ecosystems (Colin et al., 2017; Maceda-Veiga et al., 2013; Stasinakis et al., 2012).

Table 1. Physico-chemical water parameters from polluted and reference habitats analyzed on spring and summer 2014

\begin{tabular}{lcccc}
\hline & \multicolumn{2}{c}{ Spring } & \multicolumn{2}{c}{ Summer } \\
& $\begin{array}{c}\text { Reference } \\
25 / 3 / 14\end{array}$ & $\begin{array}{c}\text { Polluted } \\
21 / 3 / 14\end{array}$ & $\begin{array}{c}\text { Reference } \\
16 / 7 / 14\end{array}$ & $\begin{array}{c}\text { Polluted } \\
15 / 7 / 15\end{array}$ \\
& & & & \\
\hline Flow $(\mathrm{L} / \mathrm{s})$ & 239.5 & 241.2 & 28.4 & 124.0 \\
Temperature $\left({ }^{\circ} \mathrm{C}\right)$ & 14.2 & 16.9 & 19.0 & 23.0 \\
Oxygen $(\mathrm{mg} / \mathrm{L})$ & 7.2 & 6.2 & 7.1 & 8.0 \\
Conductivity $(\mu \mathrm{S} / \mathrm{cm})$ & 728 & 3680 & 709 & 4777 \\
$\mathrm{pH}$ & 8.1 & 8.3 & 7.1 & 8.3 \\
$\mathrm{NH}_{3}(\mathrm{mg} / \mathrm{L})$ & 0.04 & 0.40 & 0.04 & 5.30 \\
$\mathrm{NO}_{2}(\mathrm{mg} / \mathrm{L})$ & 0.01 & 0.90 & 0.01 & 5.51 \\
$\mathrm{NO}_{3}(\mathrm{mg} / \mathrm{L})$ & 0.13 & 19.6 & 0.06 & 10.6 \\
$\mathrm{PO}_{4}(\mathrm{mg} / \mathrm{L})$ & 0.1 & 1.0 & 0.1 & 0.8 \\
$\mathrm{SO}_{4}(\mathrm{mg} / \mathrm{L})$ & 15.8 & 414.1 & 17.9 & 464.0 \\
$\mathrm{Cl}(\mathrm{mg} / \mathrm{L})$ & 40.0 & 987 & 31.9 & 1088 \\
\hline
\end{tabular}

143

\subsection{Per- and polyfluoroalkyl substances}

Seven PFAS were detected in muscle tissue by UPLC; perfluorononanoic acid (PFNA), perfluorooctane sulfonic acid (PFOS), perfluorodecanoic acid (PFDA), perfluoroundecanoic acid (PFUnA), perfluorodecane sulfonic acid (PFDS), perfluorododecanoic acid (PFDoA) and perfluorotridecanoic acid (PFTriDA). Information regarding the chemicals and reagents, sample extraction and analysis technique applied is provided in the Supplementary material. The analysis of PFAS confirmed that, in both spring and summer, fish from the polluted habitat 
Table 2. Per- and polyfluoroalkyl substances detected in muscle

\subsection{Cortisol extraction}

167 Blood - Blood was collected by puncture of the caudal vein with a heparinized insulin syringe and kept on ice until transported back to the laboratory. Samples were then centrifuged at 1500 $\mathrm{x} \mathrm{g}$ for $5 \mathrm{~min}$ at $4{ }^{\circ} \mathrm{C}$ and the plasma collected was stored at $-20^{\circ} \mathrm{C}$ until analysis.

170 Scales - Whole body scales were removed with a small scalpel and all of them where used for

171 hormone extraction. In studies using larger species, the optimal methodology should employ

172 one or a small number of scales while taking into account that ontogenetic and regenerated scales can accumulate different hormone concentrations, at least in common carp under laboratory conditions (Aerts et al., 2015). In the present study, extraction of cortisol from scales was performed following the procedure described by Carbajal et al., (2018). Briefly, scales were

176 washed three times with isopropanol and, once dry, they were minced with a ball mill (Retsch, 177 MM2 type, Germany). Then, $50 \mathrm{mg}$ of each powdered sample was incubated in methanol for 
18h. This sample mass was used chosen following the methods of previous studies on other cumulative matrices (Davenport et al., 2006; Fourie et al., 2016; Lattin et al., 2011). After extraction, samples were centrifuged and the supernatant was evaporated. Dried extracts were reconstituted with enzyme immunoassay (EIA) extraction buffer and immediately stored at -20 ${ }^{\circ} \mathrm{C}$ until analysis. Not enough scale sample mass could be collected from some specimens (reference $n=8$; polluted $n=6$ ) due to their small body size, consequently, from these individuals only cortisol from plasma was analysed.

\subsection{Cortisol analysis and validation tests}

Cortisol concentrations from plasma and scales were measured by enzyme immunoassay (Cortisol EIA KIT; Neogen ${ }^{\circledR}$ Corporation, Ayr, UK). Although the EIA kit comes already species-specifically validated, each assay needs an exhaustive biochemical validation for the species and sample of interest (Buchanan and Goldsmith, 2004). Biochemical validation was conducted using methods previously described for cortisol analysis in scales of goldfish (Carassius auratus) by EIA (Carbajal et al., 2018). Plasma and scale extracts from 10 different specimens were pooled for assay validation. Intra-assay coefficient of variation (CV) from all duplicated samples analysed was calculated for precision assessment. The specificity was evaluated with the linearity of dilution. Accuracy was assessed through the spike-and-recovery test. And the sensitivity of the test was given by the smallest amount of hormone that the assay is able to distinguish and measure for each matrix.

\subsection{Statistical analysis}

The computer program R software (R-project, Version 3.0.1, R Development Core Team, University of Auckland, New Zealand) was used to analyse the data. A $p<0.05$ was considered statistically significant. Shapiro-Wilk tests were used to test for normality of data, and logtransformed when appropriate.

Pearson's correlation coefficients (r) were used to test the relationship between SCC and plasma cortisol concentrations (PCC) in the two sites separately. We explored whether season and habitat quality could potentially influence PCC and SCC using linear regression models with 
sex, $K$ and GSI as covariates. Covariates were omitted from the final models since they were non- significant $(p>0.05)$. We used Tukey post-hoc tests to distinguish the seasonal variations in SCC. We assessed seasonal and habitat differences in $K$, GSI and sex by applying ANOVAs and Student's t-test for quantitative variables, and chi-squared for sex. Additionally, sex differences in PCC and SCC were analysed with a Student's t-test.

In the biochemical validation, Pearson's correlation was used to evaluate the correlation between obtained and expected values from serial dilutions. The same statistical test was applied to calculate the relationship of the parallelism between cortisol standards and the serially diluted pool extract.

\section{RESULTS}

\subsection{Sex and morphological variables}

The morphological variables and sex distribution of Catalan chub in both assessments (habitat quality and seasonal variability) are shown in Table 3. Significant differences in $K$ between individuals from the reference and polluted habitats were detected $(p<0.01)$. A seasonal change in $K$ was also observed with significantly higher values detected on the early summer $(p<0.01)$. Neither differences between sites nor a seasonal variation in GSI and the sex distribution was detected $(p>0.05)$.

\subsection{Biochemical validation of the EIA}

The sensitivity of the assay was $0.07 \mathrm{ng}$ cortisol $/ \mathrm{ml}$ for plasma and $0.08 \mathrm{ng}$ cortisol $/ \mathrm{ml}$ for scales extracts. Intra-assay CV for plasma and scales samples was $8.80 \%$ and $6.60 \%$ respectively. In the dilution test, obtained and expected cortisol concentrations were significantly correlated both in plasma and scales $(\mathrm{r}=0.99, p<0.01)$. The average of the recovery percentage from spike-and-recovery test was $107.6 \pm 10.0 \%($ mean \pm SD) for plasma and $101.1 \pm 4.8 \%($ mean \pm SD) for scales validation. These results demonstrate that the EIA kit used is precise, specific, 
231 likewise demonstrated in other fish species (Carbajal et al., 2018).

Table 3. Sex distribution ( $(\%)$ ) and values of K and GSI (mean \pm SD) of individuals sampled from reference and degraded habitats (habitat quality) and individuals sampled during the early spring, middle spring and early summer (seasonal variability). Different letters indicate statistical difference between sites (habitat quality) and among sampling efforts (seasonal influence) $(\mathrm{p}<0.01)$.

\begin{tabular}{|c|c|c|c|c|c|}
\hline \multirow[b]{2}{*}{ Variable } & \multicolumn{2}{|c|}{ Habitat quality } & \multicolumn{3}{|c|}{ Seasonal influence } \\
\hline & Reference & Polluted & Early spring & $\begin{array}{c}\text { Middle } \\
\text { spring }\end{array}$ & Early summer \\
\hline Sex (males) & $5(62.5 \%)^{\mathrm{a}}$ & $10(52.6 \%)^{\mathrm{a}}$ & $5(62.5 \%)^{\mathrm{a}}$ & $5(62.5 \%)^{\mathrm{a}}$ & $13(65.0 \%)^{\mathrm{a}}$ \\
\hline$K$ & $1.02 \pm 0.05^{\mathrm{a}}$ & $1.12 \pm 0.08^{\mathrm{b}}$ & $1.02 \pm 0.05^{\mathrm{a}}$ & $1.01 \pm 0.06^{\mathrm{a}}$ & $1.26 \pm 0.11^{\mathrm{b}}$ \\
\hline GSI & $3.76 \pm 2.17^{\mathrm{a}}$ & $3.27 \pm 1.98^{\mathrm{a}}$ & $3.76 \pm 2.17^{\mathrm{a}}$ & $4.47 \pm 2.30^{\mathrm{a}}$ & $5.36 \pm 2.76^{\mathrm{a}}$ \\
\hline
\end{tabular}

$K$, Fulton's condition factor; GSI, gonadosomatic index

232

233

234

\subsection{Cortisol levels}

Fish from the reference site displayed significant correlation between SCC and PCC $(r=0.41, p$ $=0.04)$, however, such correlation was not significant in fish inhabiting the polluted habitat $(\mathrm{r}=$ 0.44, $p=0.20$ ). Comparison between habitats revealed that the degraded site presented significantly lower PCC levels ( $p=0.02$; Fig. 1A), but no differences on SCC between sites were detected ( $p=0.56$; Fig. 1B). Seasonal differences were detected on SCC ( $p=0.01$; Fig. 2B), although PCC remained constant ( $p=0.90$; Fig. 2A). Post-hoc tests revealed that in early summer, SCC were significantly higher compared to levels detected in early $(p=0.04)$ and middle spring $(p=0.03)$. Sex differences in PCC $(p=0.09)$ and SCC were not detected $(p=$ $0.76)$.

\section{DISCUSSION}

Fish scales have been recently recognized as a biomaterial that accumulates cortisol, hence the present study explores the applicability of scales cortisol analysis as a bioindicator in wild environments. We provide further evidence that scales may accumulate cortisol in proportion to circulating concentrations. Moreover, results of this study suggest that the deposition of cortisol 
in fish scales is probably not influenced by the habitat quality, but rather by seasonal intrinsic or extrinsic factors.

251 An essential way to validate whether scale cortisol reflect the HPI axis activity is to evaluate if

252 hormone levels deposited in the matrix correlate to those detected in plasma from the same 253 individuals (Cook, 2012; Sheriff et al., 2011). Documentation on this relationship, however, has never been reported before in free-ranging animals. We should point out that, although we could not specifically validate the time course elevation in blood cortisol concentrations, as supported by the literature, we were probably measuring stress-induced PCC given that we collected blood $1 \mathrm{~h}$ following exposure to a stressor (Mommsen et al., 1999; Pankhurst, 2011). From our study, a significant correlation was found between cortisol levels in scales and blood in fish from the reference habitat. Direct hormone correlations between blood and cumulative matrices (e.g., hair and feathers) may not always be expected. Similar to our findings, correlations have been successfully determined between corticosterone levels in blood and feathers, probably the bird cumulative matrix analogous to fish scales. Interestingly, the correspondence was evident by using stress-induced blood corticosterone levels (Bortolotti et al., 2008) and when blood hormone values were the highest of the overall studied period (Fairhurst et al., 2013a). Blood and scale cortisol concentrations predominantly differ in the time frames that are reflected by the measurements. While PCC offers an instantaneous snapshot view of the HPI axis activity, SCC are hypothesized to provide an integrated measure. Our results, therefore, are unlikely to indicate that a single blood cortisol value reflects the total SCC. The connection between both matrices provides evidence that scales could be integrating cortisol relative to bloodstream concentrations, at least in the non-stressful habitat since such relationship was not mirrored in

271 fish from the polluted site.

272 The lack of correlation in the polluted habitat is perhaps not surprising. When PCC were contrasted between fish from habitats of different contaminant load, fish from the polluted site exhibited lower PCC. This different response in either site could be due to the effect of certain aquatic contaminants, since there is strong evidence that can inhibit post-stress cortisol levels 
277 the stress response (Marentette et al., 2012; Norris et al., 1999). Importantly, altered PCC may suggest a reduced capacity of the fish to tolerate subsequent or additional stressors from their natural settings (Angelier and Wingfield, 2012; Odermatt et al., 2006). Consequently, any potential relationship between PCC and SCC could have been masked as a result of the pollutants' interference. Despite this, the possibility of a sample size with not enough statistical power to identify the relationship between matrices cannot be completely ruled out. As observed in other cumulative matrices (Ashley et al., 2011; Fairhurst et al., 2013a), fish scales accumulate lower amounts of cortisol compared to levels detected in plasma. Therefore, the collection of a certain quantity of scales is imperative in order to reliably extract and detect cortisol concentrations in fish scales. In the present study some small body-sized specimens where discarded since not enough sample mass could be collected. Hence increasing sample size will probably aid in determining if such between-matrix relationship differs among populations due to the habitat characteristics.

Since scales are hypothesized to accumulate cortisol relative to concentrations in bloodstream (Aerts et al., 2015), this latter result observed on PCC should also be reflected in SCC. Nevertheless, whether cortisol is incorporated into the scales from the surrounding water, especially in polluted sites with higher water cortisol levels (Weizel et al., 2018) should not be completely ruled out. In the present study, we did not detect differences in SCC when comparing a polluted and a reference site. Previous studies have described that habitat degradation can affect the cortisol response to a stressor, while keeping baseline levels unaltered (Belanger et al., 2016; Blevins et al., 2013, 2012; King et al., 2016). Considering that basal cortisol concentrations in Catalan chub potentially remained unaffected by the habitat quality, our results are consistent with the idea that cumulative matrices, such as feather, hair and shed skin, are more influenced by basal levels of the hormone than by acute and non-recurrent stress responses (Ashley et al., 2011; Berkvens et al., 2013; Fairhurst et al., 2013a; Tallo-Parra et al., 
2017). Understanding the influence of acute and short elevations of cortisol in SCC seems vital in order to deepen its value as a measure of long-term HPI axis activity. Experimental manipulations of plasma cortisol levels at several intensities (from moderate to severe) and durations (from minutes to days) would provide value to the biological relevance of SCC and thus help for the appropriate interpretation of results. Although further experimental work is needed to clarify this effect, our findings may suggest that the contribution of single acute stressors to scale cortisol is probably small.

Despite the fact that SCC stayed the same between habitats, there was a seasonal change in SCC. A growing body of literature has demonstrated seasonality on GC levels in different taxa (Baker et al., 2013; Cockrem, 2013; Wingfield and Romero, 2015). In line with this assumption, the present study provides novel evidence that also SCC could vary seasonally. On one hand, the lack of differences detected between early and middle spring samplings could indicate that cortisol levels in scales are relatively stable and that SCC may probably not change in the context of minor life changes. On the other, the increment of SCC from middle spring to summer suggests that during the time between these two sampling efforts something promoted the activation of the HPI axis. As a consequence, circulating levels of the hormone could have been increased, incorporating higher amounts of cortisol into the scales. In agreement with previous reports on Catalan chub (Aparicio, 2016; Sostoa et al., 1990), the increment observed in GSI from spring to summer suggests that the period studied covered the species' breeding season. Breeding is a life-history stage energetically expensive (Bonier et al., 2011; Romero, 2002) largely known to influence the HPI axis activity (Dantzer et al., 2014; Wingfield and Sapolsky, 2003). In this context, the breeding season in Catalan chub has already been described to be a physiologically demanding live-history stage distinguished by a high percentage of blood alterations (Colin et al., 2017). Therefore, the increase in SCC concurring with the breeding period of the species could be partly influenced by the common energetic needs of individuals during reproduction (Milla et al., 2009; Schreck, 2010). 
Besides the biological demands driven by the breeding season, the period studied coincides with a series of short-term changes in the habitat conditions that are worth mentioning. As demonstrated by the physico-chemical analysis, the water flow was drastically reduced from spring to summer in the reference site. Drought periods and consequently low water flow conditions are typically observed in this geographic area, and are related to reduced habitat quantity and quality (Jessop et al., 2003; Maceda-Veiga et al., 2009). Interestingly, events such as drought are known to trigger stress responses in many vertebrate species (Baker et al., 2013; Jessop et al., 2003; Tokarz and Summers, 2011; Wikelski et al., 2001). Variation in water temperature is another environmental variable that should be considered when studying wild fish, since several authors have demonstrated its influence on cortisol stress responses (Blevins et al., 2012; Cook et al., 2011; Meka and McCormick, 2005; Quinn et al., 2010). In order to cope with subtle changes in the environment, such as the above mentioned, healthy individuals are predicted to increase GC secretion (Wikelski and Cooke, 2006), leading to higher circulating cortisol levels (Bonier et al., 2009). Therefore, the seasonal differences observed in SCC could also be driven or exacerbated by short-term changes, probably of a certain intensity, in the environmental conditions (Wingfield et al., 2011). Some authors have concluded that in order to detect hormonal changes in cumulative matrices a more intense and/or prolonged activation of the HPI axis in needed (Fairhurst et al., 2013a, 2013b; Lattin et al., 2011). Although empirical evidence of the extended change in the energetic demands is scarce, our results could suggest that fluctuations in SCC may become apparent once the HPI axis has been challenged or stimulated for a period of at least 3 months (period span between the $2^{\text {nd }}$ and $3^{\text {rd }}$ sampling), regardless of whether it is driven by intrinsic or extrinsic causes.

The relationship between cortisol levels and intrinsic factors related to the animals' biology such as body condition or the reproductive status has been emphasized by many authors (Baker et al., 2013; Cook et al., 2012; Sheriff et al., 2011; Vera et al., 2017). Despite not detecting an influence of $K$ nor GSI on SCC, fish from the polluted habitat presented higher body condition 

inhabiting polluted environments has been described (Goodbred et al., 2015). Colin and colleagues (2017) reported similar findings in Catalan chub by using the Scaled Mass Index instead of the Fulton's condition index. As these authors suggested, eutrophication of fresh water can result in better food quality. Note that some pollutants, especially those with endocrine disrupting effects, have obesogenic activity in humans and other vertebrates (Holtcamp, 2012; Ismail et al., 2017) including fish (Lyche et al., 2010). Thus a differing contaminant profile between habitats could also drive to the contrasting body condition observed. Furthermore, fish at the early summer increased their body condition compared to the previous assessments. Several factors other than stress, such as seasonal and developmental modifications, can also induce changes in condition indices (Barton et al., 1998; Mahé et al., 2018), possibly explaining why body condition varied as the season progressed.

In fish, sex has been less frequently considered in comparison with studies in other vertebrates, yet it is known that cortisol levels can vary due to sex differences (Baker et al., 2013). In this study we did not detect differences in PCC nor SCC between males and females. While this is the first time that sex differences in SCC are evaluated, our results provide valuable data for studies in wildlife where sex is a factor usually difficult to control, especially in species without sexual dimorphism, and when the number of individuals collected needs to be kept low for ethical reasons.

In conclusion, while comparison of fish inhabiting habitats of different contaminant load suggests that SCC may not be a promising bioindicator of environmental quality, the SCC increase concurring with an energetically costly period for the fish species studied strongly supports the idea that the analysis of cortisol in scales could reveal changes in the HPI axis activity. This study, therefore, indicates that cortisol levels in scales are more likely to be influenced by mid-term, intense energetically demanding periods rather than by long-term 
382 stressors. The degree to which cortisol deposition in scales is affected by external (drought, 383 temperature) and/or internal (reproduction) factors needs to be further explored. Studies 384 including samples collected over extended periods of time (e.g. a year), along with the 385 assessment of other physiological endpoints of stress responses would be of interest to determine whether, when and which factors influence the cortisol deposition in fish scales. 


\section{REFERENCES}

Aerts, J., Metz, J.R., Ampe, B., Decostere, A., Flik, G., De Saeger, S., 2015. Scales Tell a Story on the Stress History of Fish. PLoS One 10, e0123411. https://doi.org/10.1371/journal.pone.0123411

Angelier, F., Wingfield, J.C., 2012. Importance of the glucocorticoid stress response in a changing world: Theory, hypotheses and perspectives. Gen. Comp. Endocrinol. 190, 118128. https://doi.org/10.1016/j.ygcen.2013.05.022

Aparicio, E., 2016. Peixos continentals de Catalunya. Ecologia, conservació i guia d'identificació, 2016th ed. Lynx Edicions, Barcelona.

Ashley, N.T., Barboza, P.S., Macbeth, B.J., Janz, D.M., Cattet, M.R.L., Booth, R.K., Wasser, S.K., 2011. Glucocorticosteroid concentrations in feces and hair of captive caribou and reindeer following adrenocorticotropic hormone challenge. Gen. Comp. Endocrinol. 172, 382-391. https://doi.org/10.1016/j.ygcen.2011.03.029

Baker, M.R., Gobush, K.S., Vynne, C.H., 2013. Review of factors influencing stress hormones in fish and wildlife. J. Nat. Conserv. 21, 309-318. https://doi.org/10.1016/j.jnc.2013.03.003

Barton, B.A., Morgan, J.D., Vljayan, M., 1998. Physiological and Condition-Related Indicators of Environmental Stress in Fish. Biol. Indic. Aquat. Ecosyst. Stress 111-148.

Belanger, C.B., Vera-Chang, M.N., Moon, T.W., Midwood, J.D., Suski, C.D., Cooke, S.J., 2016. Seasonal variation in baseline and maximum whole-body glucocorticoid concentrations in a small-bodied stream fish independent of habitat quality. Comp. Biochem. Physiol. -Part A Mol. Integr. Physiol. 192, 1-6. https://doi.org/10.1016/j.cbpa.2015.10.027

Berkvens, C.N., Hyatt, C., Gilman, C., Pearl, D.L., Barker, I.K., Mastromonaco, G.F., 2013. Validation of a shed skin corticosterone enzyme immunoassay in the African House Snake (Lamprophis fuliginosus) and its evaluation in the Eastern Massasauga Rattlesnake (Sistrurus catenatus catenatus). Gen. Comp. Endocrinol. 194, 1-9. https://doi.org/10.1016/j.ygcen.2013.08.011

Blevins, Z.W., Effert, E.L., Wahl, D.H., Suski, C.D., 2012. Land use drives the physiological properties of a stream fish. Ecol. Indic. 24, 224-235. https://doi.org/10.1016/j.ecolind.2012.06.016

Blevins, Z.W., Wahl, D.H., Suski, C.D., 2013. Reach-Scale Land Use Drives the Stress Responses of a Resident Stream Fish. Physiol. Biochem. Zool. 87, 113-124. https://doi.org/10.1086/670732

Bonier, F., Martin, P.R., Moore, I.T., Wingfield, J.C., 2009. Do baseline glucocorticoids predict fitness? Trends Ecol. Evol. 24, 634-642. https://doi.org/10.1016/j.tree.2009.04.013 
Bonier, F., Moore, I.T., Robertson, R.J., 2011. The stress of parenthood? Increased glucocorticoids in birds with experimentally enlarged broods. Biol. Lett. 7, 944-946. https://doi.org/10.1098/rsbl.2011.0391

Bortolotti, G.R., Marchant, T. a., Blas, J., German, T., 2008. Corticosterone in feathers is a long-term, integrated measure of avian stress physiology. Funct. Ecol. 22, 494-500. https://doi.org/10.1111/j.1365-2435.2008.01387.x

Brewer, S.K., Rabeni, C.F., Papoulias, D.M., 2008. Comparing histology and gonadosomatic index for determining spawning condition of small-bodied riverine fishes. Ecol. Freshw. Fish 17, 54-58. https://doi.org/10.1111/j.1600-0633.2007.00256.x

Buchanan, K.L., Goldsmith, A.R., 2004. Noninvasive endocrine data for behavioural studies: the importance of validation. Anim. Behav. 67, 183-185. https://doi.org/10.1016/j.anbehav.2003.09.002

Carbajal, A., Monclús, L., Tallo-Parra, O., Sabes-Alsina, M., Vinyoles, D., Lopez-Bejar, M., 2018. Cortisol detection in fish scales by enzyme immunoassay: Biochemical and methodological validation. J. Appl. Ichthyol. 1-4. https://doi.org/10.1111/jai.13674

Cockrem, J.F., 2013. Individual variation in glucocorticoid stress responses in animals. Gen. Comp. Endocrinol. 181, 45-58. https://doi.org/10.1016/j.ygcen.2012.11.025

Colin, N., Maceda-Veiga, A., Monroy, M., Ortega-Ribera, M., Llorente, M., de Sostoa, A., 2017. Trends in biomarkers, biotic indices, and fish population size revealed contrasting long-term effects of recycled water on the ecological status of a Mediterranean river. Ecotoxicol. Environ. Saf. 145, 340-348. https://doi.org/10.1016/j.ecoenv.2017.07.048

Cook, N.J., 2012. Review : Minimally invasive sampling media and the measurement of corticosteroids as biomarkers of stress in animals. Can. J. Anim. Sci. 92, 227-259. https://doi.org/10.4141/CJAS2012-045

Cook, K. V., O’Connor, C.M., Gilmour, K.M., Cooke, S.J., 2011. The glucocorticoid stress response is repeatable between years in a wild teleost fish. J. Comp. Physiol. A Neuroethol. Sensory, Neural, Behav. Physiol. 197, 1189-1196. https://doi.org/10.1007/s00359-011-0680-3

Cook, K. V, Connor, C.M.O., Mcconnachie, S.H., Gilmour, K.M., Cooke, S.J., 2012. Condition dependent intra-individual repeatability of stress-induced cortisol in a freshwater fi sh. Comp. Biochem. Physiol. Part A 161, 337-343. https://doi.org/10.1016/j.cbpa.2011.12.002

Dantzer, B., Fletcher, Q.E., Boonstra, R., Sheriff, M.J., 2014. Measures of physiological stress: a transparent or opaque window into the status, management and conservation of species? Conserv. Physiol. 2, 1-18. https://doi.org/10.1093/conphys/cou023.

Davenport, M.D., Tiefenbacher, S., Lutz, C.K., Novak, M. a, Meyer, J.S., 2006. Analysis of endogenous cortisol concentrations in the hair of rhesus macaques. Gen. Comp. 
Elliott, D.G., 2000. Microscopic functional anatomy: Integumentary system: Chapter 17, in: Ostrander, G.K. (Ed.), The Laboratory Fish. Academic Press, pp. 271-306. https://doi.org/10.1016/B978-012529650-2/50023-8

Fairhurst, G.D., Marchant, T. a, Soos, C., Machin, K.L., Clark, R.G., 2013a. Experimental relationships between levels of corticosterone in plasma and feathers in a free-living bird. J. Exp. Biol. 216, 4071-81. https://doi.org/10.1242/jeb.091280

Fairhurst, G.D., Vögeli, M., Serrano, D., Delgado, A., Tella, J.L., Bortolotti, G.R., 2013b. Can synchronizing feather-based measures of corticosterone and stable isotopes help us better understand habitat-physiology relationships? Oecologia 173, 731-43. https://doi.org/10.1007/s00442-013-2678-8

Fourie, N.H., Brown, J.L., Jolly, C.J., Phillips-Conroy, J.E., Rogers, J., Bernstein, R.M., 2016. Sources of variation in hair cortisol in wild and captive non-human primates. Zoology 119, 119-125. https://doi.org/10.1016/j.zool.2016.01.001

Gesto, M., Soengas, J.L., Míguez, J.M., 2008. Acute and prolonged stress responses of brain monoaminergic activity and plasma cortisol levels in rainbow trout are modified by PAHs (naphthalene, $\beta$-naphthoflavone and benzo(a)pyrene) treatment. Aquat. Toxicol. 86, 341351. https://doi.org/10.1016/j.aquatox.2007.11.014

Goodbred, S.L., Patiño, R., Torres, L., Echols, K.R., Jenkins, J.A., Rosen, M.R., Orsak, E., 2015. Are endocrine and reproductive biomarkers altered in contaminant-exposed wild male Largemouth Bass (Micropterus salmoides) of Lake Mead, Nevada/Arizona, USA? Gen. Comp. Endocrinol. 219, 125-135. https://doi.org/10.1016/j.ygcen.2015.02.015

Holtcamp, W., 2012. Obesogens: An Environmental Link to Obesity. Environ. Health Perspect. 120, 63-68. https://doi.org/10.1289/ehp.120-a62

Hontela, A., Rasmussen, J.B., Audet, C., Chevalier, G., Penfield, A.D., 1992. Impaired Cortisol Stress Response in Fish from Environments Polluted by PAHs, PCBs, and Mercury 283, $278-283$.

Ismail, N.A.H., Wee, S.Y., Aris, A.Z., 2017. Multi-class of endocrine disrupting compounds in aquaculture ecosystems and health impacts in exposed biota. Chemosphere 188, 375-388. https://doi.org/10.1016/j.chemosphere.2017.08.150

Jessop, T.S., Tucker, A.D., Limpus, C.J., Whittier, J.M., 2003. Interactions between ecology, demography, capture stress, and profiles of corticosterone and glucose in a free-living population of Australian freshwater crocodiles. Gen. Comp. Endocrinol. 132, 161-170. https://doi.org/10.1016/S0016-6480(03)00078-9

Johnstone, C.P., Reina, R.D., Lill, A., 2012. Interpreting indices of physiological stress in freeliving vertebrates. J. Comp. Physiol. B Biochem. Syst. Environ. Physiol. 182, 861-879. https://doi.org/10.1007/s00360-012-0656-9 
Jorgensen, E.H., Maule, A.G., Evenset, A., Christensen, G., Bytningsvik, J., Frantzen, M., Nikiforov, V., Faught, E., Vijayan, M.M., 2017. Biomarker response and hypothalamuspituitary-interrenal axis functioning in Arctic charr from Bjornoya $\left(7^{\circ} 30^{\prime} \mathrm{N}\right)$, Norway, with high levels of organohalogenated compounds. Aquat. Toxicol. 187, 64-71. https://doi.org/10.1016/j.aquatox.2017.03.017

Killen, S., Adriaenssens, B., Marras, S., Claireaux, G., Cooke, S.J., 2016. Context dependency of trait repeatability and its relevance for management and conservation of fish populations. Conserv. Physiol. 4, 1-19. https://doi.org/10.1093/conphys/cow007

King, G.D., Chapman, J.M., Cooke, S.J., Suski, C.D., 2016. Stress in the neighborhood: Tissue glucocorticoids relative to stream quality for five species of fish. Sci. Total Environ. 547, 87-94. https://doi.org/10.1016/j.scitotenv.2015.12.116

Lattin, C.R., Reed, J.M., DesRochers, D.W., Romero, L.M., 2011. Elevated corticosterone in feathers correlates with corticosterone-induced decreased feather quality: a validation study. J. Avian Biol. 42, 247-252. https://doi.org/10.1111/j.1600-048X.2010.05310.x

Leblond, V.S., Bisson, M., Hontela, A., 2001. Inhibition of Cortisol Secretion in Dispersed Head Kidney Cells of Rainbow Trout ( Oncorhynchus mykiss ) by Endosulfan , an Organochlorine Pesticide 56, 48-56. https://doi.org/10.1006/gcen.2000.7556

Lyche, J., Nourizadeh-Lillabadi, R., Almaas, C., Stavik, B., Berg, V., Skåre, J., Alestrøm, P., Ropstad, E., 2010. Natural mixtures of persistent organic pollutants (POP) increase weight gain, advance puberty, and induce changes in gene expression associated with steroid hormones and obesity in female zebrafish. J Toxicol Env. Heal. A. 73, 1032-57. https://doi.org/10.1080/15287394.2010.481618

Maceda-Veiga, A., Monroy, M., Navarro, E., Viscor, G., de Sostoa, A., 2013. Metal concentrations and pathological responses of wild native fish exposed to sewage discharge in a Mediterranean river. Sci. Total Environ. 449, 9-19. https://doi.org/10.1016/j.scitotenv.2013.01.012

Maceda-Veiga, A., Salvadó, H., Vinyoles, D., de Sostoa, A., 2009. Outbreaks of Ichthyophthirius multifiliis in redtail barbs Barbus haasi in a mediterranean stream during drought. J. Aquat. Anim. Health 21, 189-194. https://doi.org/10.1577/H08-054.1

Madliger, C.L., Love, O.P., 2014. The need for a predictive, context-dependent approach to the application of stress hormones in conservation. Conserv. Biol. 28, 283-287. https://doi.org/10.1111/cobi.12185

Mahé, K., Bellamy, E., Delpech, J.P., Lazard, C., Salaun, M., Vérin, Y., Coppin, F., TraversTrolet, M., 2018. Evidence of a relationship between weight and total length of marine fish in the North-eastern Atlantic Ocean: physiological, spatial and temporal variations. J. Mar. Biol. Assoc. United Kingdom 98, 617-625. https://doi.org/10.1017/S0025315416001752 
Marentette, J.R., Tong, S., Balshine, S., 2012. The cortisol stress response in male round goby (Neogobius melanostomus): Effects of living in polluted environments? Environ. Biol. Fishes 96, 723-733. https://doi.org/10.1007/s10641-012-0064-8

Matas, D., Keren-Rotem, T., Koren, L., 2016. A method to determine integrated steroid levels in wildlife claws. Gen. Comp. Endocrinol. 230-231, 26-28. https://doi.org/10.1016/j.ygcen.2016.03.020

Meka, J.M., McCormick, S.D., 2005. Physiological response of wild rainbow trout to angling: Impact of angling duration, fish size, body condition, and temperature. Fish. Res. 72, 311322. https://doi.org/10.1016/j.fishres.2004.10.006

Milla, S., Wang, N., Mandiki, S.N.M., Kestemont, P., 2009. Corticosteroids: Friends or foes of teleost fish reproduction? Comp. Biochem. Physiol. - A Mol. Integr. Physiol. 153, 242251. https://doi.org/10.1016/j.cbpa.2009.02.027

Miller, L.L., Rasmussen, J.B., Palace, V.P., Hontela, A., 2009. Physiological stress response in white suckers from agricultural drain waters containing pesticides and selenium. Ecotoxicol. Environ. Saf. 72, 1249-1256. https://doi.org/10.1016/j.ecoenv.2008.09.018

Moberg, J., Mench, G.P., 2000. The Biology of Animal Stress. Basic principles and implications for animal welfare. New York, CABI Pub. https://doi.org/10.1079/9780851993591.0000

Mommsen, T.P., Vijayan, M.M., Moon, T.W., 1999. Cortisol in teleosts : dynamics , mechanisms of action, and metabolic regulation. Rev. Fish Biol. Fish. 211-268. https://doi.org/10.1023/A:1008924418720

Norris, D.O., Donahue, S., Dores, R.M., Lee, J.K., Tammy, A., Ruth, T., Woodling, J.D., 1999. Impaired Adrenocortical Response to Stress by Brown Trout, Salmo trutta, Living in Metal-Contaminated Waters of the Eagle River, Colorado 8, 1-8.

Odermatt, A., Gumy, C., Atanasov, A.G., Dzyakanchuk, A.A., 2006. Disruption of glucocorticoid action by environmental chemicals: Potential mechanisms and relevance. J. Steroid Biochem. Mol. Biol. 102, 222-231. https://doi.org/10.1016/j.jsbmb.2006.09.010

Palme, R., 2005. Measuring fecal steroids: Guidelines for practical application. Ann. N. Y. Acad. Sci. 1046, 75-80. https://doi.org/10.1196/annals.1343.007

Pankhurst, N.W., 2011. The endocrinology of stress in fish: an environmental perspective. Gen. Comp. Endocrinol. 170, 265-75. https://doi.org/10.1016/j.ygcen.2010.07.017

Pottinger, T.G., Henrys, P.A., Williams, R.J., Matthiessen, P., 2013. The stress response of three-spined sticklebacks is modified in proportion to effluent exposure downstream of wastewater treatment works. Aquat. Toxicol. 126, 382-392. https://doi.org/10.1016/j.aquatox.2012.09.002

Pottinger, T.G., Williams, R.J., Matthiessen, P., 2016. A comparison of two methods for the assessment of stress axis activity in wild fish in relation to wastewater effluent exposure. 
Quabius, E.S., Balm, P.H.M., Wendelaar Bonga, S.E., 1997. Interrenal stress responsiveness of tilapia (Oreochromis mossambicus) is impaired by dietary exposure to PCB 126 . Gen. Comp. Endocrinol. 108, 472-482. https://doi.org/10.1006/gcen.1997.7003

Quinn, A.L., Rasmussen, J.B., Hontela, A., 2010. Physiological stress response of Mountain Whitefish (Prosopium williamsoni) and White Sucker (Catostomus commersoni) sampled along a gradient of temperature and agrichemicals in the Oldman River, Alberta. Environ. Biol. Fishes 88, 119-131. https://doi.org/10.1007/s10641-010-9622-0

Romero, L.M., 2004. Physiological stress in ecology: lessons from biomedical research. Trends Ecol. Evol. 19, 249-55. https://doi.org/10.1016/j.tree.2004.03.008

Romero, L.M., 2002. Seasonal changes in plasma glucocorticoid concentrations in free-living vertebrates. Gen. Comp. Endocrinol. 128, 1-24. https://doi.org/10.1016/S00166480(02)00064-3

Russell, E., Koren, G., Rieder, M., Van Uum, S., 2012. Hair cortisol as a biological marker of chronic stress: Current status, future directions and unanswered questions. Psychoneuroendocrinology 37, 589-601. https://doi.org/10.1016/j.psyneuen.2011.09.009 Schreck, C.B., 2010. Stress and fish reproduction: The roles of allostasis and hormesis. Gen. Comp. Endocrinol. 165, 549-556. https://doi.org/10.1016/j.ygcen.2009.07.004

Schreck, C.B., Tort, L., Farrell, A.P., Brauner, C.J., 2016. Biology of stress in fish, 2016th ed. Academic Press.

Scott, G.R., Sloman, K. a, 2004. The effects of environmental pollutants on complex fish behaviour: integrating behavioural and physiological indicators of toxicity. Aquat. Toxicol. 68, 369-92. https://doi.org/10.1016/j.aquatox.2004.03.016

Sheriff, M.J., Dantzer, B., Delehanty, B., Palme, R., Boonstra, R., 2011. Measuring stress in wildlife: techniques for quantifying glucocorticoids. Oecologia 166, 869-87. https://doi.org/10.1007/s00442-011-1943-y

Sostoa, A., Allué, R., Bas, C., Casals, F., Casaponsa, J., Castillo, M., Doadrio, I., 1990. Peixos, in: Història Natural Dels Països Catalans. Enciclopèdia Catalana, Barcelona, p. 487.

Stasinakis, A.S., Mermigka, S., Samaras, V.G., Farmaki, E., Thomaidis, N.S., 2012. Occurrence of endocrine disrupters and selected pharmaceuticals in Aisonas River (Greece) and environmental risk assessment using hazard indexes. Environ. Sci. Pollut. Res. 19, 15741583. https://doi.org/10.1007/s11356-011-0661-7

Tallo-Parra, O., Lopez-Bejar, M., Carbajal, A., Monclús, L., Manteca, X., Devant, M., 2017. Acute ACTH-induced elevations of circulating cortisol do not affect hair cortisol concentrations in calves. Gen. Comp. Endocrinol. 240, 138-142. https://doi.org/10.1016/j.ygcen.2016.10.007

Tokarz, R.R., Summers, C.H., 2011. Stress and Reproduction in Reptiles, Hormones and 
Reproduction of Vertebrates - Volume 3. Elsevier. https://doi.org/10.1016/B978-0-12374930-7.10007-X

Vera, F., Zenuto, R., Antenucci, C.D., 2017. Expanding the actions of cortisol and corticosterone in wild vertebrates: A necessary step to overcome the emerging challenges. Gen. Comp. Endocrinol. 246, 337-353. https://doi.org/10.1016/j.ygcen.2017.01.010

Weizel, A., Schlüsener, M.P., Dierkes, G., Ternes, T.A., 2018. Occurrence of Glucocorticoids, Mineralocorticoids, and Progestogens in Various Treated Wastewater, Rivers, and Streams. Environ. Sci. Technol. 52, 5296-5307. https://doi.org/10.1021/acs.est.7b06147

Wikelski, M., Cooke, S.J., 2006. Conservation physiology. Trends Ecol. Evol. 21, 38-46. https://doi.org/10.1016/j.tree.2005.10.018

Wikelski, M., Romero, L.M., Snell, H.L., 2001. Marine iguanas oiled in the Galápagos. Science (80-. ). 292, 437-438. https://doi.org/10.1126/science.292.5516.437c

Wingfield, J.C., Kelley, J.P., Angelier, F., 2011. What are extreme environmental conditions and how do organisms cope with them ? Curr. Zool. 57, 363-374.

Wingfield, J.C., Romero, L.M., 2015. Tempests, Poxes, Predators, and People: Stress in Wild Animals and How They Cope. Published to Oxford Scholarship Online. https://doi.org/DOI: 10.1093/acprof:oso/9780195366693.001.0001

Wingfield, J.C., Sapolsky, R.M., 2003. Reproduction and Resistance to Stress: When and How. J. Neuroendocrinol. 15, 711-724. https://doi.org/10.1046/j.1365-2826.2003.01033.x 
628 Figure 1. Boxplots of (A) plasma cortisol concentrations (ng cortisol/ml plasma) and (B) scale 629 cortisol concentrations (ng cortisol/g scale) in Catalan chub from degraded and reference 630 habitats. The asterisk indicates differences in plasma cortisol concentrations between habitats $(p$ $631=0.02)$.

632 Figure 2. Boxplots of seasonal comparisons on (A) plasma cortisol concentrations (ng 633 cortisol/ml plasma) and (B) scale cortisol concentrations ( $\mathrm{g}$ cortisol/g scale) in Catalan chub 634 from the reference habitat. The asterisk indicates that at the early summer scales cortisol levels 635 were significantly higher compared to early $(p=0.04)$ and mid $(p=0.03)$ spring levels.

636

637 